\title{
Linus Pauling's quest for the structure of proteins
}

\author{
István Hargittai
}

Published online: 6 December 2009

(C) Springer Science+Business Media, LLC 2009

\begin{abstract}
Linus Pauling, arguably the greatest chemist of the twentieth century, never publicly admitted that there was a race for the determination of the structure of the most important biopolymers. But according to his competitors there was a race, in fact, there were two, and Pauling won one and lost the other. He had a tremendous amount of ideas, many of them worthless, but a few were spectacular. Not only did he make seminal discoveries, he was also a master of announcing them in a most dramatic way. Eventually, Pauling shifted toward politics and controversial issues, but his science ensured him his place among the greats. Here, we follow Pauling's route to the discovery of the alpha-helix; the defeat of the star-studded British team in the same quest; and a seemingly unrelated story about the fate of the theory of resonance that assured Pauling's victory yet at the same time it was excommunicated in the Soviet Union.
\end{abstract}

Keywords Linus Pauling - Structure of proteins . Theory of resonance $\cdot$ Peptide bond $\cdot$ Alpha-helix

For most of the first half of the twentieth century a large number of scientists were not even sure biopolymers existed. The view survived for long that the principal components of living matter were in a colloidal state, that is, conglomerates of smaller molecules. It was only in 1953 when Hermann Staudinger was awarded the Nobel Prize in

\footnotetext{
I. Hargittai $(\bowtie)$

Department of Inorganic and Analytical Chemistry and Materials Structure and Modeling Research Group of the Hungarian Academy of Sciences, Budapest University of Technology and Economics, P.O. Box 91, H-1521 Budapest, Hungary e-mail: istvan.hargittai@gmail.com
}

Chemistry for his discoveries about macromolecules that the existence of polymers was irrevocable accepted. By then, though, a lot about the structures of the biologically important macromolecules had been discovered. Thus, during the first half of the twentieth century, the efforts to establish the nature of biological substances and to uncover their structures went in parallel.

The British father and son team, W. H. Bragg and W. L. Bragg, pioneered the technique of X-ray diffraction crystallography in 1913, with the son playing the leading role. When the two Braggs were awarded the Nobel Prize in 1915, the son became the youngest ever Nobel laureate and has stayed the youngest to this date. After a hiatus due to World War I, this field took off spectacularly in the realm of small molecular systems. As early as the 1920s, fibrous materials were subjected to X-ray diffraction for the first time by Michael Polanyi in Herman Mark's laboratory at the Kaiser Wilhelm Institute in Berlin. Polanyi's experiments on cellulose indicated the presence of crystallites in cellulose and they were oriented in the direction of the fiber axis. He could not have performed a full structure analysis at that time, but Mark and Polanyi observed characteristic changes on stretching the cellulose fibers. Mark was to become one of the century's foremost polymer chemists. When he was forced out of Germany, he moved to his native Vienna where he helped one of his students, Max Perutz to be accepted as a doctoral student in Cambridge, UK, in 1935. Perutz would become a key player in the quest for the structure of proteins. But he was only slowly moving to the area of his ultimate success when Linus Pauling was already a major force in the field.

Pauling came from a humble background, but he was ambitious. He lost his father when he was 9 years old and his mother found it difficult to cope with her obligations. She certainly did not appreciate her son's intentions to stay 
in school even when it was no longer mandated for him to continue his studies. Pauling's schoolings were not at top places, and when in 1922 he went to the California Institute of Technology (as it was later; Caltech in short) it was far from the preeminent research-oriented institution into which it would develop. But the school was as ambitious as its new student, and there were visionary movers of it who were set to making Caltech a top-notch institution of higher education and research. They were smart enough not only looking into the distant future and only for big names to recruit from faraway places, but recognized in Pauling the potentials of a star scientist who would even challenge British preeminence in the science of chemical structures.

When Pauling started his doctoral studies with Roscoe Dickenson, a fresh home-grown $\mathrm{PhD}$ in X-ray crystallography at Caltech, this field was less than a decade old. Pauling became engaged in the determination of the structure of many inorganic and organic molecules and amassed a large amount of information about them during the ensuing decade. What kind of information was that? It was about the geometrical arrangement of the atoms in the molecules and the arrangement of the molecules in the crystals.

Not all the modern knowledge was to be had at Caltech at the time, and not even in other laboratories in the United States. The leading country of science was Germany and a few other places in Europe, and Pauling_like many other aspiring American scientists-paid pilgrimage to a series of European research centers in order to learn from the likes of Arnold Sommerfeld in Munich and Erwin Schrödinger in Zurich. They were both physicists, but Pauling's aim was not to transform himself into a physicist. Rather, his goal was to apply the latest discoveries in physics, and above all the new quantum mechanics, to solving a wealth of problems in chemistry in which he proved to be unique.

The most intriguing question in chemistry at that time was about the forces that keep the atoms together in a molecule, that is, about the nature of the chemical bond. If there is anything truly associated with Pauling's name, it is the understanding the nature of the chemical bond. He used the achievements of modern physics, the experimental information about the geometry of molecules and his thinking, to put together a theory. He then kept refining it in accordance with the emergence of the latest experimental information. The science of chemistry has a great deal of intuitive approach in it, very often stemming from a desire to represent on paper what the chemists experience in the laboratory. Thus, for example, they started using a straight line connecting the symbols of two elements to represent their bonding without really understanding anything about what that straight line represented. Nowadays when we know so much about what it means, we still find this straight line an excellent representation of the chemical bond. Lewis's description of the covalent bond in 1916 was not much less intuitive than this; nonetheless he made a big step forward. He introduced the idea of the shared electron pair, meaning the covalent bond between two atoms. During the late 1920s two physicists, Walter Heitler and Fritz London used the new quantum mechanics and their sophisticated mathematical apparatus to rigorously describe this covalent bond. It was so rigorous that it was too sophisticated for most chemists to understand it let alone to apply it to solving their problems that were usually more complex than the hydrogen molecule for which Heitler and London had worked out their theory.

Linus Pauling bridged this gap in a series of brilliant articles in the Journal of the American Chemical Society. Eventually he developed his ideas and his repository of structural information into a bestseller The Nature of the Chemical Bond [1]. Its last, third edition appeared in 1960 and many of the later stars of chemistry benefited from it by getting their introduction to the intricacies of this branch of science. A new book would be timely, but nobody seems brave enough to try filling Pauling's shoes in producing a new comprehensive monograph about the chemical bond.

Had Pauling produced his series of articles about the chemical bond, and nothing else, he would have already written his name into the annals of the history of chemistry. However, he did not limit his interest to theoretical studies. He utilized X-ray crystallography broadly and was constantly on the lookout for new techniques. While in Europe, he visited Herman Mark's laboratory in Ludwigshafen, Germany (where he was at the time), and Mark introduced a new experimental technique to his visitor for the determination of molecular structure, gas-phase electron diffraction. It was similar to X-ray crystallography, but there were two major differences. It used electrons rather than $\mathrm{X}$-rays and the target was not a crystal but a gaseous sample in which the molecules had no well-defined order in their mutual arrangements.

One of the great advantages of using electrons was the very high intensity of the interaction between electrons and molecules. Thus, the duration of the required interaction was measured in minutes rather than many hours as with X-rays. The other important advantage was that in the gaseous sample the molecules were by themselves and their structures were not impacted by the closeness of their neighbors. For the X-ray technique, the molecules were required to be able to form a crystal in the first place, and there was no such requirement for using the electron diffraction technique. The structures determined by the new technique depended only by the molecule itself and not by the way they were arranged relative to each other as was the case in the crystal. Other limitations of the new technique, however, have restricted it from becoming so widely used as X-ray crystallography, which truly has been the preeminent tool for uncovering the structures of biopolymers. 
Mark's industrial laboratory was not the proper environment to expand the studies of molecular structures and he happily offered Pauling to take the new technique with him to Caltech. Mark even supplied him with the blueprints of his apparatus. Pauling not only introduced the gas-phase electron diffraction technique quickly in the United States, but he and his student, Lawrence Brockway further developed it. They added a mathematical step to handling the experimental data that made it possible to extract structural information in a graphically direct and attractive way from the probability density distribution of the internuclear distances in the molecule (usually it is referred to as the radial distribution curve, which is a misnomer). From the experiment to reading off the curves directly the distances between atoms in simple molecules took only a few days' work.

Pauling (Fig. 1) established relationships among various experimental facts and made predictions about structures not yet investigated. He then worked out a theoretical technique based on quantum mechanics, but simple enough for a broad circle of chemists, to describe molecular structures. It was called the valence-bond or VB theory and it was one of the two major theoretical approaches developed over the decades. The other is the molecular orbital or MO theory. The VB theory builds the molecules from individual atoms linked by electron-pair bonds. For chemists, the VB theory appealed as more straightforward, alas, it did not stand well the test of time. The MO theory has proved more amenable to computations, which itself has become a major thrust in modern structural chemistry. However, for a long time the VB theory dominated the field.

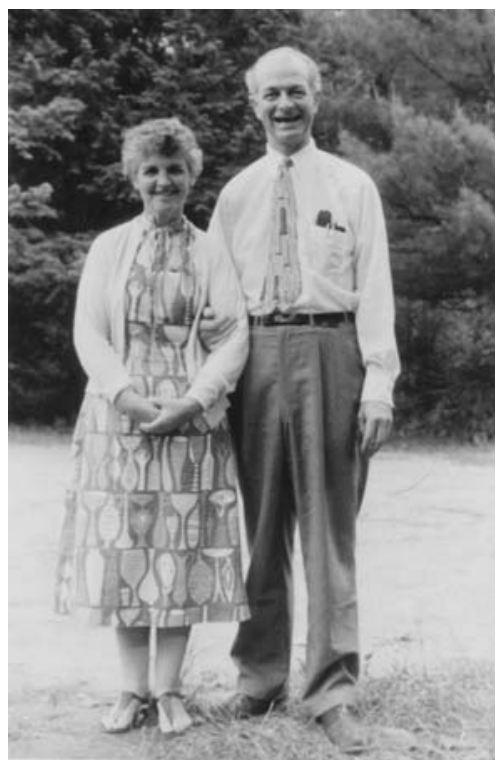

Fig. 1 Ava and Linus Pauling (photograph by and courtesy of Karl Maramorosch, Scarsdale, NY)
An important feature of the VB theory was that a molecular structure could be described by a set of "resonating" structures. This did not mean that each structure in such a set would be considered as present individually, but that the sum of these resonating structures represented the emerging structure better than any other description at the time. It needs to be stressed that what the resonance theory provides is merely a model, an approach, rather than a unique reflection of reality. There were proponents and opponents of the theory as is the case with most theories. Yet the resonance theory proved to be eminently useful for Linus Pauling-who was one of its initiators-in his quest for the protein structure. It happened so that this theory showed him the way and brought him a resounding victory over his competitors who lacked this tool and could not arrive at the right solution.

Pauling was advancing in a systematic manner in his quest for building up structural chemistry. First, he busied himself with inorganic substances and after the first 10 years he moved to organic substances. Among the organic molecules he often observed structures in which the lengths of the bonds between atoms were intermediate between single bonds and double bonds, so the theory of resonance came in handy in their understanding and description. Today, chemists no longer tend to think in terms of purely single bonds and double bonds, or triple bonds for that matter, and, accordingly, the utility of the resonance theory has largely disappeared, but in the 1930s it was considered to be of great help.

As Pauling was learning more and more about the structures of relatively simple molecules, in the mid-1930s, it occurred to him that he might as well make an attempt to learn about larger systems. He was aware of the importance of biopolymers and that the understanding of their structures might be a step toward understanding biological processes. Proteins were an obvious choice, because they were the most important biopolymers. At that time nucleic acids were already known, and their building blocks, the nucleotides, had been identified, but the nucleic acids were not considered to be of great significance. There was a hypothesis by Phoebus Levene about the tetranucleotide structure that was based on an erroneous observation that the four nucleotides in nucleic acid were present in equal amounts [2]. Hence, the nucleic acids were thought to be dull, uninteresting molecules, not capable of carrying any great amount of information.

When Pauling started thinking about protein structures, the first protein to attract his attention was hemoglobin, which is the vehicle of carrying oxygen in our organism. Incidentally, the British group engaged in protein structure studies had also selected hemoglobin for their target; their choice was independent of Pauling's interest. At the end of the 1920s, Gilbert Adair in Cambridge, UK, 
showed that the hemoglobin molecule consists of four units each with an iron atom, and each iron could bind an oxygen atom. Pauling formulated a theory about the oxygen uptake of hemoglobin and the structural features of this molecule related to its function of disposing of and taking up oxygen.

His interest in protein structures was further whetted when a visiting scientist and protein specialist, Alfred Mirsky of the Rockefeller Institute, spent the academic year 1935-1936 in his laboratory. They jointly studied the phenomenon of denaturation of proteins by heat or chemical substances, and formulated a theory about it. In this theory, they described the native protein as having a regularly folded structure in which hydrogen bonds provided the stability of the structure. Hydrogen bonding was a recently discovered phenomenon; it was becoming recognized as a crucial mode of interaction in chemical structures and especially in those of biological importance. In retrospect, it was a pivotal discovery, but its significance emerged only gradually over the years. For many biological molecules it is the hydrogen bonds that keep their different parts together.

Pauling postulated that the subsequent amino acid units are linked to each other in the folded protein molecule not only by the normal peptide bond but also by hydrogen bonding that is facilitated by the folding of the protein, which brings the participating atoms sufficiently close to each other for such interactions. In Pauling's and Mirsky's conclusion, when the protein molecule is denatured it undergoes complete or partial unfolding accompanied by breaking the hydrogen bonds. This was a hypothesis, because they knew practically nothing about the nature of folding; finding more about it occupied Pauling's mind for the next 15 years.

By the time Pauling became engaged in this research it had been established from rudimentary X-ray diffraction patterns that there might be two principal types of protein structure. Keratin fibers, such as hair, horn, porcupine quill, and fingernail belonged to one, and silk to the other. The foremost British crystallographer of fibers, William $\mathrm{T}$. Astbury showed in the early 1930s that the diffraction pattern of hair underwent changes when it was stretched. He called the one producing the normal pattern alpha keratin and the other, which was similar to the pattern from silk, beta keratin. In 1937, Pauling set out to determine the structure of alpha keratin. He did not just want to rely on a single source of information. He planned to use all his accumulated knowledge in structural chemistry and find the best model that would make sense on this background and would be compatible with the X-ray diffraction pattern.

There was one piece of information from X-ray diffraction that seemed to be a good point of reference and that was the structural unit—whatever it would be-along the axis of the protein molecules repeated at the distance of 5.1 angstrom. He also knew the dimensions of the peptide group, that is, the characteristic sizes of the group linking the amino acids to each other in the protein chain. The $\mathrm{C}-\mathrm{N}$ bond in the peptide linkage was not simply a single bond, but it was not a purely double bond either. Pauling's involvement with the resonance theory taught him that the emerging structure could be represented by two resonating structures

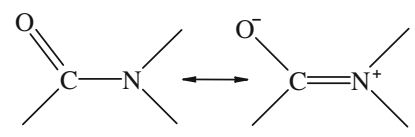

Hence, the resonance theory suggested that the $\mathrm{C}-\mathrm{N}$ bond in the peptide linkage had a partial double bond character. From the accumulated structural information he also knew that the bonds around a double bond are all in the same plane. This was a very important piece of information because rather than taking into account all kinds of rotational forms with respect to the peptide bond, he could assume that it was a planar configuration. This assumption greatly reduced the number of possible models he had to consider for describing the structure of alpha keratin. Nonetheless, at this time Pauling was unable to find a model that would fit the X-ray diffraction pattern and he postponed further study on protein structures.

During the ensuing years Pauling and his newly arrived associate, Robert Corey, an expert in X-ray crystallography, carried out a large amount of experimental work determining the structures of individual amino acids and simple peptides. At some time every doctoral student in Pauling's laboratory was supposed to determine the structure of an amino acid for his $\mathrm{PhD}$ dissertation. The study was interrupted by World War II, but continued vigorously upon its conclusion. Pauling returned to the question of the structure of alpha keratin in 1948 while he was a visiting professor at Oxford University in England.

Not only had the amount of experimental information in the meantime expanded considerably, but Pauling could take a more detached view of the problem in his renewed efforts. When he was looking for the solution more than a decade before, he was bothered by the knowledge that his model was supposed to accommodate the possible presence of 20 different amino acids in the protein chain. At this time, in 1948, he decided to ignore their differences and assumed them to be equivalent for the purpose of his model. This was yet another example of Pauling's ability to distinguish between essential features and those that could be ignored in building his models.

Pauling remembered a theorem in mathematics he learned about at Caltech a quarter of a century before. It stated that the most general operation to convert an 
asymmetric object into an equivalent asymmetric object is a rotation-translation and that repeated application of this operation produces a helix. Here the asymmetric objects are the amino acids constituting the protein chain; the rotation should take place about the molecular axis of the protein; and the translation is the movement ahead along the chain. The amount of rotation was such that took the chain from one amino acid to the next while the peptide group was kept planar, and this operation was being repeated and repeated all the time. An additional restriction was keeping the adjacent peptide groups apart at a distance that corresponded to hydrogen bonding. In Pauling's model the turn of the protein chain did not involve an integral number of amino acids-he did not consider this a requirement whereas his British counterparts did. This was yet another relaxed feature of the structure that served him well in finding the best model whereas it served as an unnecessary restriction for his competitors.

Pauling - ever the model builder-sketched a protein chain on a piece of paper and folded the paper while looking for structures that would satisfy the assumptions he had made (Fig. 2). He found two and called one the alpha helix and the other the gamma helix, the latter being much less probable than the former. He determined the distance between repeating units in the protein chain and noticed a marked difference between his estimation from the model and the experimental value from the diffraction pattern. This was disappointing but the model was so attractive and so sensible that Pauling had little doubt in its correctness. Nonetheless, he decided to wait with its publication until the discrepancy would be understood. His confidence was enhanced when he visited the British group involved also in the structure elucidation of proteins and Max Perutz showed him his diffraction patters. From the X-ray

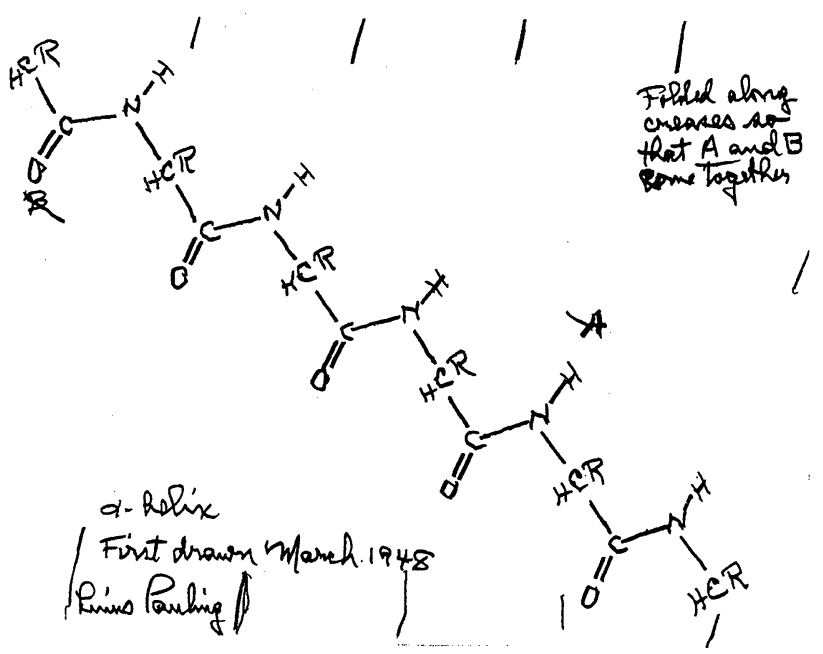

Fig. 2 Linus Pauling's sketch of the polypeptide chain in 1948. When he folded the paper along the creases, the alpha-helix appeared [3] (Fig. 3)

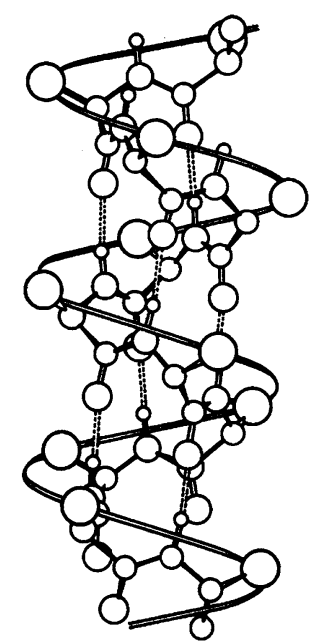

Fig. 3 Model of alpha-helix with 3.7 amino acid residues per pitch after [4]

diagrams it was obvious to Pauling-though not yet to Perutz-that the structure was alpha helix. Pauling did not say anything to Perutz.

When Pauling returned to Pasadena, he and his associates double checked all his calculations and found no errors in them. In the meantime, after about a year, Bragg, Perutz, and John Kendrew of Cambridge, UK, published a big article about protein structures and communicated about 20 models, none of which contained a planar peptide group and none of which described alpha keratin satisfactorily [5]. Finally, Pauling decided to ignore the discrepancy of the repeat distance between his model and the experimental observation and he and his associates published the alpha helix.

Eventually, the origin of the discrepancy was understood; it was caused by the alpha helices twisting together into ropes. This interaction between the chains caused a change in the experimental data as compared to what it would be for a single chain for which the model had been constructed. Thus, Pauling's alpha helix was confirmed even in this detail. The alpha helix has proved to be a great discovery because it is a conspicuously frequent structural feature of proteins.

Pauling's approach to solving this complex problem was exemplary in focusing on what was essential and ignoring what had little consequence. When it turned out that the turn about the chain did not correspond to an integer number of amino acids, hinting at less than perfect symmetry, he did not let himself bothered by this. He thus expanded the realm of crystallography toward structures that were not part of classical crystallography yet included literally vital substances. It was also noteworthy that he could skip a decade in working on this most important discovery without much danger of others scooping him. 
They almost did, but only in their timing and not in knowledge, because his knowledge proved to be superior to anyone in his field at that time.

Pauling must have sensed the precarious nature of the situation and restrained himself from revealing crucial information to Perutz during his visit to Cambridge (vide supra). The Cambridge X-ray diffraction pattern showed the helical nature but Perutz did not think about it and thus did not notice it whereas for Pauling it provided additional evidence of the correctness of his model. This episode showed both his competitive spirit and his self-discipline. Finally, Pauling was sure enough in himself and his model that he went ahead with publishing the alpha helix without having yet resolved the remaining (apparent) discrepancy between his model and the available experimental evidence. First they published a short note [6], followed by a longer article [7] and soon they wrote seven more papers to report their findings.

Pauling was a master in creating publicity for his discoveries. When he prepared for announcing the discovery of the alpha helix it was to be in a big lecture hall at Caltech. The model stood on the rostrum, but it was under a cover, waiting to be unveiled, just as a sculpture would be, and it came toward the end of Pauling's lecture. When it was finally unveiled, the effect was dramatic and the audience was stunned by its beauty. I myself experienced the mesmerizing effect of Pauling's lecturing at the University of Oslo in 1982. He covered the board with complicated formulas and from time to time he looked at the audience as if checking whether we were duly impressed. Otherwise, the formulas were not at all necessary for us to understand the points he was making. He was already an octogenarian, but watching him gave an impression of a young assistant professor who came for interview and was presenting his research with the usual arrogance of such scenes. During the lunch following the lecture he was more vigorous than the rest, led the discussion, and fired away questions, mostly answering them himself.

In research publications there is no place for the human sides of the discoveries and Pauling wrote up the story of his alpha helix discovery separately, but it never appeared while he was alive. It was published 2 years after he died when I was running a chemical magazine and his former secretary of his last 20 years, Dorothy Monro, suggested to bring it out there. Research papers usually lack the human element and the blind alleys in research, so this paper by Pauling was especially valuable for our understanding how this particular discovery happened [3].

The Cambridge group suffered a defeat in this case, which was especially heavy for W. Lawrence Bragg to bear, because he was the pioneer of X-ray crystallography and the American group came out on top in their undeclared race. It was not possible to pinpoint a single reason for this defeat, but it was a crucial difference that Pauling could limit the number of possible models because of his superior knowledge of structural chemistry. The Cambridge group had no such guideline although it could have. It turned out that Lord Todd the soon to be Nobel laureate organic chemist who worked in the next building to Perutz's and Kendrew's laboratory had told Bragg that the peptide bond had some double-bond character. Bragg, however, could not from this piece of information make any conclusion about the configuration of the peptide bond, namely, that it was planar.

Years after this fiasco, Perutz complained about their lack of knowledge of the planarity of the peptide group. He blamed the Medical Research Council (MRC) for having him denied the use of a Rockefeller Fellowship for travel to America in 1948. The Secretary of the MRC thought that rather than going to learn from the Americans, the Americans should come and learn from the British. In hindsight, Perutz thought that he could have learned about the peptide bond planarity from Pauling had he been allowed to travel [8]. Of course, he could have just walked across the street to visit Lord Todd for the same information.

It is not at all sure whether had Perutz visited Pauling he would have learned from Pauling as much as he might have supposed in retrospect. We have seen Pauling withholding his observation from Perutz that he had noticed the evidence of helical structure on Perutz's X-ray diffraction diagram. During his Oxford sojourn, Pauling wrote to Corey back to Pasadena that he felt uncomfortable about the English competition. In their turn, the British considered protein crystallography their own territory. It was not only that the Braggs discovered X-ray crystallography and that Astbury was a pioneer in taking X-ray pictures of proteins. It was also J. Desmond Bernal who had prepared the first ever X-ray diffraction diagrams of a single-crystal protein - a pepsin single crystal-that clearly showed the possibility of deducing atomic positions from it. This was in 1934. In the future Nobel laureate X-ray crystallographer Dorothy Hodgkin's description, "that night, Bernal, full of excitement, wandered about the streets of Cambridge, thinking of the future and how much it might be possible to know about the structure of proteins if the photographs he had just taken could be interpreted in every detail" [9]. The British self-confidence in dominating this field reached such proportion that Astbury and Bernal divided it by a gentlemen's agreement between the two of them. They decided that Bernal would take up the investigation of the crystalline substances and Astbury the fibrous ones [10].

Perutz on his part, for their failure blamed Astbury's X-ray diffraction picture, which showed a discrepancy between the repeat distances as compared with reasonable structures, a discrepancy —as we have seen-Pauling daringly disregarded. Perutz was disheartened when he found 
Pauling's paper about the alpha helix model. He devised an additional X-ray experiment that gave further evidence for the correctness of Pauling's result, something that Pauling had missed. When Perutz reported his finding to Bragg, Bragg asked him, "How did you think of that?" Perutz's response was that it was because he was so angry that he hadn't thought of the structure himself. To which Bragg replied coldly, "I wish I'd made you angry earlier" [11]. Perutz told me this story in 1997, and he used this phrase as the title of his next book. Perutz might have thought that Pauling would be pleased that he provided additional evidence for alpha helix, but was disappointed by Pauling's reaction, which was clearly dismissing.

Pauling's fascination with proteins served him well in his focusing his attention to their structures at a crucial period in twentieth century science. However, he continued his protein bias even when the next big task appeared before structural chemistry that was the structure of nucleic acids. Pauling entered that race too, but there is ample evidence that Pauling did not concentrate on it with the intensity and dedication as he had done for the protein structures. In case of the quest for the structure of nucleic acids he was defeated by the British teams. Pauling published an erroneous triple helix and he was not in possession of the best X-ray diffraction patterns of nucleic acids that were available at the early 1950s either. As is well known, those patterns were produced at King's College in London and the winning double helix model came out from the Cavendish Laboratory in Cambridge, UK, but this is a different story.

We can add a footnote about Pauling's theory of chemical resonance, which served him so well in the above story. At about the same time, this theory was in the center of attack by rabid ideologists in the Soviet Union [12]. The culmination was a 4-day conference in Moscow in 1951, organized by the Soviet Academy of Sciences. Leading Soviet chemists, physicists, philosophers, and others attended the meeting. A small but vocal group of chemists attacked the theory of resonance as an ideological aberration and together with it quantum theory and the science of the West. They insisted on returning to traditional Russian values and offered their own worthless theories. Excellent scientists suffered ruthless criticism for having applied the theory of resonance in their work, and they, in turn, offered humiliating self-criticism.

The affair has been referred to as the great Soviet resonance controversy and it was a chapter in the anti-science events following World War II that touched biology even more severely. Physics was spared in the last minute due to its decisive role in producing nuclear weapons. Stalin's terror did everything to protect his empire from even the slightest influence by the West, the purest sciences included. There was irony in this story in that Pauling was a friend of the Soviet Union and suffered persecution in the McCarthy era, but this was not yet known in the Soviet Union. In 1993, I asked Pauling for his comments about this affair. He appeared as if he misunderstood it or did not want to understand it. He wrote that it took years "for the chemists in the Soviet Union to get a proper understanding of the resonance theory" ([12], p 5). In reality, they understood it well enough and applied it with great success, that is, until 1951, when the main proponents of the theory lost their jobs. If it was a consolation, their lives were spared in contrast with some of their biologist colleagues in a similar ideological controversy.

Acknowledgment Our research is being supported in part by the Hungarian Scientific Research Foundation (OTKA Nos. K60365 and T046183).

\section{References}

1. Pauling L (1960) The nature of the chemical bond and the structure of molecules and crystals: an introduction to modern structural chemistry (Third edition, First edition, 1939). Cornell University Press, Ithaca, NY

2. Hargittai I (2009) Struct Chem 20:753-756

3. Pauling L (1996) Chem Intell 2(1):32-38

4. Corradini P (1982) In: Carra S, Parisi F, Pasquon I, Pino P (eds) Giulio Natta: present significance of his scientific contribution. Editrice di Chimica, Milano, p 134

5. Bragg WL, Kendrew JC, Perutz MF (1950) Proc R Soc 203A:321-357

6. Pauling L, Corey RB (1950) J Am Chem Soc 72:5349

7. Pauling L, Corey RB, Branson HR (1951) Proc Natl Acad Sci USA 37:205-211

8. Olby R (1994) The path to the double helix: the discovery of DNA. Dover Publications, New York, p 291

9. Hodgkin DC, Riley DP (1968) In: Rich A, Davidson N (eds) Structural chemistry and molecular biology. WH Freeman, San Francisco and London, pp 15-28

10. Bernal JD (1968) Labour Monthly, pp 323-326

11. Hargittai I (2002) Candid science II: conversations with famous biomedical scientists (edited by Magdolna Hargittai). Imperial College Press, London, p 288

12. Hargittai I (2000) Candid science: conversations with famous chemists (edited by Magdolna Hargittai). Imperial College Press, London, pp 8-13 